\title{
The Case Of ABC Tech And Its Variable Interest Entities: When Is Consolidation Required?
}

Tim Kelley, University of San Diego, USA

Loren Margheim, University of San Diego, USA

\begin{abstract}
In this case, students interpret GAAP requirements with respect to the accounting for variable interest entities. The case requires students (who take on the role of an audit manager) to critically apply GAAP requirements to the fact situation facing a fictitious technology company. The fictitious company is highly leveraged and has two large variable interest entities and the CEO of the company is determined to keep these entities off of his company's financial statements. The case requires critical thinking and judgment to determine if one or both of the company's variable interest entities must be consolidated according to current GAAP. Students are to summarize their findings in a memo to the audit partner in charge of the local office.
\end{abstract}

Keywords: Variable Interest Entities; Consolidation; Contingent Liabilities; Related Party Transactions

\section{INTRODUCTION}

$\mathrm{n}$ this case, you are to play the role of an audit manager working for a large CPA firm with an office located in San Diego. About a month ago you met Ruth Cousins, the CFO of ABC Tech, at a conference sponsored by the Financial Executives International (FEI). At the conference, Ruth mentioned that her company was looking for a new audit firm. She also told you that her company has several variable interest entities (VIE's) and that the accounting for these entities continues to be a challenge.

Over the last month, you (and some other professionals at your firm) have met with the CEO, CFO and audit committee for $\mathrm{ABC}$ Tech. Now at this point, your firm is getting prepared to submit a bid in an attempt to become the company's new auditors.

As part of your due diligence work, you reviewed this year's preliminary unaudited financial statements of ABC Tech (for the year ended December 31, 2010). You determine that the company is highly leveraged with a debt-to-assets ratio of $85 \%$ (Liabilities $=\$ 5.1$ billion and Assets $=\$ 6.0$ billion). You also determine that if the company's variable interest entities were consolidated, the company's debt-to-assets ratio would be even higher. In the last decade, $\mathrm{ABC}$ Tech has been growing rapidly and has developed into a major player in its industry. The company would be the largest audit for your firm's San Diego office if your firm gets this contract.

$\mathrm{ABC}$ Tech has started up some large variable interest entities in the last few years (most notably Vimco and South Tech), but earnings growth for ABC Tech has slowed recently. Net Income for ABC Tech was $\$ 30$ million in 2006, \$113 million in 2007, \$218 million in 2008, \$247 million in 2009, and \$251 million in 2010. Note that the 2010 figure for net income is unaudited.

The partner in charge of your office, Robert Blaine, is very enthusiastic about the prospect of getting this new audit client. He mentioned to you that landing this audit would look good for you when you go up for possible promotion to partner within the next two years. 
Another partner in your office, Sharon Benaron, is concerned about the firm taking on this client. She is worried about the fact that the CEO of ABC Tech, Paul Lloyd, is also on the board of one of the largest variable interest entities associated with the company (i.e., South Tech). She sees this related party involvement between these two entities as a risk factor. Additionally, she is concerned that $\mathrm{ABC}$ Tech has guaranteed considerable debt for some of its variable interest entities (e.g., Vimco and South Tech). She wonders if some of ABC Tech's variable interest entities should be consolidated in the company's financial statements. Overall, Sharon thinks that bidding on $\mathrm{ABC}$ Tech is ill advised as she believes that winning this client would entail too much risk.

Paul Lloyd is the founder of ABC Tech and is highly influential in the San Diego business community. As $\mathrm{CEO}$, he has expressed a strong desire to keep all variable interest entities off his company's balance sheet. He does not seem to be too worried about the cost of the audit, but he believes that these variable interest entities must to be kept off his company's financial statements. He has argued strongly that $\mathrm{ABC}$ Tech cannot afford to take on any more debt in its balance sheet.

Robert Blaine (normally somewhat cautious by nature) does not appear to be as concerned as Sharon Benaron about the variable interest entities. He seems to think that something can be worked out with Paul Lloyd and the management of $\mathrm{ABC}$ Tech. Robert has called you into his office to request that you write him a memo (with a copy to Sharon) to explain what current GAAP says about the circumstances under which variable interest entities need to be consolidated. He wants you to research:

- $\quad$ FIN 46(R) and FASB 167 on variable interest entities (this research is summarized in FASB ASC 810-1005)

- $\quad$ FASB 5 (summarized in FASB ASC 450) on Loss Contingencies since there is a concern about what would happen if Vimco and/or South Tech defaulted on their considerable debt

- $\quad$ any GAAP (such as FASB 57) on accounting for related party transactions

Robert wants to know if you think that $\mathrm{ABC}$ Tech needs to consolidate the results of its operations with Vimco and/or South Tech (based on the information that has been gathered at this point). Robert also wants to know if additional information needs to be collected before bidding on the audit of $\mathrm{ABC}$ Tech (or deciding to not bid on this potentially lucrative new audit client).

Below is a summary of the information that your firm has been able to gather with respect to Vimco and South Tech that can help you with the memo that Robert wants you to write.

\section{MORE INFORMATION ON VIMCO}

ABC Tech has guaranteed considerable debt for Vimco (a variable interest entity that the company set up a few years ago). See draft of a footnote disclosure (from the current year's preliminary financials) that provides more information on these contingent obligations.

Additionally, you learn from Ruth Cousins that the general partner for Vimco is Ramona Technology Corp. which is a wholly owned subsidiary of $\mathrm{ABC}$ Tech. Over the years, $\mathrm{ABC}$ Tech has consolidated its results with Ramona Technology Corp. However, since a majority of the ownership of Vimco is with its limited partners, ABC Tech has never consolidated its financial statements with Vimco.

You determine that Vimco has no governing board and that $80 \%$ of the startup capital came from its limited partners and 20\% came from Vimco's general partner, Ramona Technology (ABC Tech's wholly owned subsidiary). Per your review of the partnership agreement, you determine that the limited partners are guaranteed a $5 \%$ annual return on their investment and that $60 \%$ of any earnings above this amount would be allocated to the general partner with $40 \%$ being allocated to the limited partners. Any losses would be absorbed by the general partner.

ABC Tech's preliminary unaudited 2010 financials show (in the footnotes) that it had recorded $\$ 70$ million in gross margin on a sale from $\mathrm{ABC}$ Tech to Vimco. According to this footnote disclosure, "Company management 
asserts that this sale was normal and a similar profit would have been earned if the inventory had been sold to another party." Sharon is concerned about this transaction and wonders if recording this profit is acceptable. Sharon is also concerned that (per a recent discussion with CFO Ruth Cousins) Vimco still holds this inventory in stock as of year-end December 31, 2010 and that ABC Tech has a long-term contract with Vimco to sell Vimco a significant amount of inventory (at least $\$ 100$ million each year) over the next five years.

Ruth Cousins has provided your firm with the following 2010 financial statement information for Vimco (Table 1). Note that the 2009 financial information has been audited, while the 2010 information is unaudited:

\begin{tabular}{|c|c|c|}
\hline Assets (as of December 31, 2010) & & (millions) \\
\hline Cash & & $\$ 20$ \\
\hline Other Current Assets & & 480 \\
\hline Long-Term Assets & & $\underline{450}$ \\
\hline Total Assets & & $\$ 950$ \\
\hline Current Liabilities & & $\$ 700$ \\
\hline Long-Term Liabilities & & 300 \\
\hline Owners' Equity & & $\underline{-50}$ \\
\hline Total Liabilities and Owners' Equity & & $\$ 950$ \\
\hline (Amounts in Millions) & 2009 & 2010 \\
\hline Sales & $\$ 379$ & $\$ 421$ \\
\hline Operating Income/Loss & -8 & -72 \\
\hline Net Income/Loss & -19 & -85 \\
\hline Operating Cash Flows & -42 & -36 \\
\hline
\end{tabular}

\section{MORE INFORMATION ON SOUTH TECH}

Ruth Cousins has provided a copy of South Tech's most recent financial statements for the year ended December 31, 2010 (Table 2). Note that the 2009 figures are audited and the 2010 figures are unaudited. Overall, these financials show South Tech to be highly leveraged and operating at a net loss.

Table 2: South Tech - Financial Information

\begin{tabular}{|c|c|c|}
\hline Assets (as of December 31, 2010) & & (millions) \\
\hline Cash & & $\$ 21$ \\
\hline Other Current Assets & & 79 \\
\hline Long-Term Assets & & $\underline{500}$ \\
\hline Total Assets & & $\$ \$ \$ 600$ \\
\hline Current Liabilities & & $\$ 320$ \\
\hline Long-Term Liabilities & & 208 \\
\hline Owners' Equity & & $\underline{72}$ \\
\hline Total Liabilities and Owners' Equity & & $\$ 600$ \\
\hline (Amounts in Millions) & 2009 & 2010 \\
\hline Sales & $\$ 168$ & $\$ 195$ \\
\hline Operating Income & -14 & -19 \\
\hline Net Income/Loss & -22 & -24 \\
\hline Operating Cash Flows & -34 & -32 \\
\hline
\end{tabular}


Based on your review of ABC Tech's 2010 preliminary footnote disclosures from its unaudited financials, you determine that $\mathrm{ABC}$ Tech has guaranteed some of the outstanding liabilities for South Tech. See draft of a financial statement footnote disclosure that provides more information on these contingent obligations.

Additionally, you determine that the CEO of ABC Tech, Paul Lloyd, is also a member of the board of directors of South Tech. You determine that South Tech's governing board is fairly active and that outside shareholders own $90 \%$ of the board seats and Paul Lloyd controls the other 10\%. Furthermore, you determine that 90\% of the start-up capital for South Tech came from the outside shareholders and 10\% came from the personal funds of Paul Lloyd a few years ago when ABC Tech set up South Tech. Profits and losses are to be absorbed in proportion to the number of shares owned by shareholders.

Based on your preliminary review, there were no significant intercompany transactions between $\mathrm{ABC}$ Tech and South Tech in 2010 and there are no significant sales/purchase contracts outstanding between ABC Tech and South Tech as of December 31, 2010.

To gain more insight into the operations of $\mathrm{ABC}$ Tech (and its variable interest entities), you must analyze some of the key footnote disclosure drafts from the Company's (unaudited) 2010 financial statements. Below are excerpts from these footnotes.

\section{SELECTED EXCERPTS FROM THE "CONTINGENCIES" AND "RELATED PARTY TRANSACTIONS" NOTES TO ABC TECH'S (UNAUDITED) 2010 FINANCIAL STATEMENTS}

ABC Tech guarantees the performance of certain of its unconsolidated equity affiliates in connection with letters of credit issued on behalf of those entities. As of December 31, 2010, a total of $\$ 270$ million of such guarantees were outstanding, including \$100 million on behalf of Vimco, L.P. and $\$ 62$ million on behalf of South Tech, L.P. In addition, $\mathrm{ABC}$ Tech is a guarantor on certain liabilities of unconsolidated equity affiliates and other companies totaling approximately $\$ 870$ million at December 31,2010 , including $\$ 500$ million related to Vimco trade obligations and \$96 million related to South Tech obligations. Vimco's and South Tech's letters of credit and guarantees of trade obligations are secured by the assets of Vimco and South Tech, respectively. Management does not consider it likely that $\mathrm{ABC}$ Tech would be required to perform or otherwise incur any losses associated with the above guarantees.

In 2010, ABC Tech entered into a transaction with a limited partnership that operates under the name of Vimco (the Related Party) whose general partner's managing member is a wholly owned subsidiary of ABC Tech. The limited partners of the Related Party are unrelated to ABC Tech. Management believes that the terms of the transaction with the Related Party were reasonable compared to those which could have been negotiated with unrelated third parties. In 2010, ABC Tech sold a portion of its inventory to the Related Party (Vimco) in exchange for $\$ 20$ million cash and an $\$ 80$ million note receivable that was subsequently repaid. ABC Tech recognized gross margin of $\$ 70$ million on the sale.

\section{CASE REQUIREMENTS}

Write a memo to Robert Blaine (with a copy to Sharon Benaron) that addresses the issues that Robert and Sharon are concerned about. Only provide quotes from FASB statements when necessary. What is needed with this assignment is evidence of your critical thinking (and not an exercise in cutting and pasting from FASB Standards). Your memo needs to be very clear in its recommendations. Remember to consider any ethical issues that this case raises. Also remember, of course, to be tactful and professional in your business writing. At a minimum, your memo should address the following issues:

- Is there sufficient evidence, in your opinion, for your audit firm to insist upon consolidation with Vimco? Outline the evidence that supports or does not support consolidation with Vimco.

- Is there sufficient evidence, in your opinion, for your audit firm to insist upon consolidation with South Tech? Outline the evidence that supports or does not support consolidation with South Tech. 
- $\quad$ Does FASB ASC 450's (formerly FASB 5) concern with contingent liabilities have any bearing on this case? If so, explain the implications of this standard on the accounting for the two variable interest entities in this case.

- $\quad$ Compute the impact on ABC Tech's debt-to-assets ratio if: 1) Vimco and/or South Tech need to be consolidated with its sponsoring company or 2) FASB ASC 450 requirements dictate that ABC Tech needs to book contingent liabilities related to Vimco and/or South Tech on its balance sheet. Assess the risk that $\mathrm{ABC}$ Tech will not be able to continue as a going concern if Vimco and/or South Tech defaulted on their loans.

- What is your overall recommendation to Robert and Sharon? Do you think that your firm should bid on this potential client based on the information that has been gathered thus far?

\section{INSTRUCTOR NOTES}

This case primarily involves applying GAAP requirements to a fictitious high tech company that wants to avoid consolidating with two of its largest variable interest entities. The case materials were developed with Enron's problematic variable interest entities in mind. Specifically, the excerpted partial footnotes to ABC Tech's financial statements were adapted from the footnotes to Enron's 2000 financial statements. The case requires students (who take on the role of an audit manager) to read GAAP concerned with variable interest entities, critically apply these GAAP requirements to $\mathrm{ABC}$ Tech, and summarize their findings in a memo.

Table 3 outline the characteristics of the two VIE's in this case. These characteristics can be easily changed so that professors can reuse the assignment in subsequent semesters.

Table 3: Characteristics of VIE \#1 and VIE \#2

\begin{tabular}{|l|l|}
\hline \multicolumn{1}{|c|}{ VIE \#1-Vimco } & \multicolumn{1}{|c|}{ VIE \#2-South Tech } \\
\hline Sponsoring company guarantees 60\% of VIE debt. & Sponsoring company guarantees 30\% of VIE Debt. \\
\hline $\begin{array}{l}\text { Wholly owned subsidiary of the sponsoring company is the } \\
\text { VIE's general partner. }\end{array}$ & $\begin{array}{l}\text { CEO of the sponsoring company sits on the board of the VIE } \\
\text { and help to set up the VIE several years ago. }\end{array}$ \\
\hline VIE has negative owners' equity. & VIE's equity = 12\% of assets \\
\hline $\begin{array}{l}\text { Last year there was a major sale from the sponsoring company } \\
\text { to the VIE with a very large mark up \% (and the VIE still has } \\
\text { this inventory at year end). }\end{array}$ & $\begin{array}{l}\text { There have been no significant intercompany transactions with } \\
\text { the sponsoring company. }\end{array}$ \\
\hline $\begin{array}{l}\text { The sponsoring company has a major contract to sell a } \\
\text { significant amount of inventory to the VIE over the next 5 } \\
\text { years. }\end{array}$ & $\begin{array}{l}\text { There are no significant sales/purchase contracts between the } \\
\text { sponsoring company and the VIE }\end{array}$ \\
\hline $\begin{array}{l}\text { The VIE has no governing board. } \\
\text { control 90\% of the board seats. The CEO of the sponsoring } \\
\text { company is a board member and controls 10\% of the board } \\
\text { seats. }\end{array}$ \\
$\begin{array}{l}\text { 80\% of the start-up capital came from the limited partners and } \\
\text { 20\% came from the wholly owned subsidiary of the } \\
\text { sponsoring company that serves as the general partner for the } \\
\text { VIE. Per the partnership agreement, the limited partners are } \\
\text { guaranteed a 5\% annual return on their investment. 60\% of any } 10 \% \text { came from the personal funds of the CEO of the } \\
\text { sponsoring company. Profits and losses are to be absorbed in } \\
\text { earnings above this guaranteed amount are allocated to the } \\
\text { general partner and 40\% are allocated to the limited partners. } \\
\text { Any losses are absorbed by the general partner. }\end{array}$ & \\
\hline
\end{tabular}

Overall, there are only a few key questions that students must address. The main issues include:

- $\quad$ Does the variable interest entity, Vimco, need to be consolidated?

- $\quad$ Does the variable interest entity, South Tech, need to be consolidated?

- $\quad$ Does FASB ASC 450 (formerly FASB 5), with respect to loss contingencies, have any bearing on this case? 
- Would consolidation or application of FASB ASC 450 have an impact on ABC Tech's debt to assets ratio?

- $\quad$ Do you recommend that your firm make a bid for this audit work?

In the next section of these teaching notes we discuss current GAAP for VIE's. Subsequent sections provide a discussion on the five main questions (noted above) that students need to address in their memo, followed by a discussion on assessment and some concluding remarks.

\section{Current GAAP for Variable Interest Entities}

GAAP for VIE's follows a two-step process. Below we outline (Step \#1) identification of a VIE and (Step \#2) identification of the primary beneficiary of the VIE. For Step \#1, if an economic entity meets one of the following two criteria, then that entity is considered to be a VIE:

\section{Criterion \#1}

Is the entity one "in which equity investors do not have sufficient equity at risk for the legal entity to finance its activities without additional subordinated financial support?" [FASB ASC 810-10-05-8] Evidence that subordinated financial support is needed include: (1) VIE equity of less than $10 \%$ of assets and (2) significant guarantees of VIE debt by the sponsoring company.

Or

Criterion \#2

Is the entity one in which as a group, the holders of the equity investment at risk lack any one of the following three characteristics:

- The power, through voting rights or similar rights, to direct the activities of a legal entity that most significantly impact the entity's economic performance

- The obligation to absorb the expected losses of the legal entity

- $\quad$ The right to receive the expected residual returns of the legal entity [FASB ASC 810-10-65-2]

If either Criterion \#1 or Criterion \#2 is met, then Step \#1 is met and the economic entity in question is considered to be a VIE. If Step \#1 is met, we next need to consider Step \#2: Identification of the primary beneficiary of the VIE. A reporting entity will be considered the primary beneficiary of a VIE with a controlling financial interest in the VIE if the reporting entity meets both of the following criteria per FASB ASC 810-10-65-2:

- $\quad$ The reporting entity has "the power to direct the activities of a VIE that most significantly impact the VIE's economic performance."

- $\quad$ The reporting entity has "the obligation to absorb losses of the VIE that could potentially be significant to the VIE or the right to receive benefits from the VIE that could potentially be significant to the VIE."

If a reporting entity is considered to be the primary beneficiary of a VIE, then the reporting entity and the VIE must consolidate their financial statements.

In the section that follows, we examine the five "Case Requirement" questions that students need to address in their memo. In the first two questions, students need to apply current GAAP to determine if ABC Tech needs to consolidate with the two VIE's in this case. The remaining questions are concerned with 1) contingent obligation issues, 2) the impact of consolidation and contingent obligations on ABC Tech's debt to assets ratio, and 3) the risks associated with bidding on $\mathrm{ABC}$ Tech as a potential client. 


\section{Discussion of Case Requirements}

Below we discuss the five main issues that the case asks students to specifically address in their memos:

1. Is there sufficient evidence, in your opinion, for your audit firm to insist upon consolidation with Vimco? Outline the evidence that supports or does not support consolidation with Vimco.

Students need to apply existing GAAP to the facts associated with Vimco (VIE \#1) to support their decision to recommend consolidation or nonconsolidation. ${ }^{1}$ Overall, we believe the facts in the case (as discussed below) strongly suggest that $\mathrm{ABC}$ Tech needs to consolidate its financial statements with Vimco.

Per the facts in the case, ABC Tech does not have a direct interest in Vimco. However, ABC Tech's wholly owned subsidiary, Ramona Technology Corp., is a general partner of Vimco and owns $20 \%$ of Vimco. Therefore, $\mathrm{ABC}$ Tech has an indirect interest in Vimco. Currently, $\mathrm{ABC}$ Tech consolidates with its wholly owned subsidiary (Ramona Technology Corp.), but does not consolidate with Vimco.

Students need to determine if Vimco qualifies as a VIE related to ABC Tech (Step \#1) and if ABC Tech is the primary beneficiary of Vimco (Step \#2), making consolidation a requirement per existing GAAP.

For Step \#1, students can look to FASB ASC 810-10-05-8 for the two previously listed criteria to determine if Vimco is a VIE. As mentioned above, only one of the criteria must be met for an entity to be considered a VIE. A review of the facts in this case would suggest (discussed in detail below) that both criteria are met and therefore Vimco is a VIE.

For the first criterion, students consider if Vimco needs subordinated financial support from its sponsoring company. The facts would suggest strongly that Vimco needs this subordinated financial support since: 1) Vimco's stockholders' equity is less than $10 \%$ of its assets ${ }^{2}, 2$ ) ABC Tech guarantees about $60 \%{ }^{3}$ of Vimco's debt, and 3) Vimco has recently incurred negative operating cash flows and accrual-based net losses. Thus, the evidence suggests that Vimco is in a poor financial position and is not able to support itself (without the aid of its sponsoring company) and therefore is considered to be a VIE. ${ }^{4}$

Since the first criterion is met, students are not required to consider the second criterion since only one Step \#1 criterion needs to be met for an entity to be considered as a VIE. Though not required, here we show that the second criterion is easily met.

\footnotetext{
${ }^{1}$ Vimco, in this case, is loosely based on Enron's VIE, EOTT Energy Partners, which had much of its debt guaranteed by Enron. In fact, the partial footnote in this case, with respect to contingent liabilities, is adapted from Enron's 2000 audited financials which were included in the last Enron annual report before it collapsed in a fraud linked to the way the company reported its variable interest entities. Many of Enron's variable interest entities were treated as off balance sheet entities and only disclosed in rather oblique footnote disclosures.

${ }^{2}$ Vimco has \$-50 million in negative owners' equity suggesting that there is insufficient outside at-risk capital supporting Vimco to stand on its own without the support of ABC Tech.

${ }^{3}$ Per the most recent draft of the footnotes to ABC Tech financial statements for this year, ABC Tech guaranteed $\$ 100$ million of Vimco's debt related to its letters of credit and, additionally, ABC Tech guaranteed $\$ 500$ million of Vimco's trade obligations. Overall, ABC Tech had guaranteed $\$ 600$ million of Vimco's liabilities. This total can be compared with the total debt in Vimco's balance sheet. Vimco was shown to have $\$ 700$ million in current liabilities and $\$ 300$ million in long-term liabilities for a total debt burden of $\$ 1,000$ million. Overall, ABC Tech is guaranteeing more than half of Vimco's debt ( $\$ 600$ million debt guarantee divided by $\$ 1,000$ million total debt $=60 \%$ ) which suggests that $\mathrm{ABC}$ Tech really sees Vimco as an extension of its own operations.

${ }^{4}$ As an historical footnote, we note here that in response to the Enron fiasco, the FASB with FIN 46(R) superseded the old 3\% rule (which said that $3 \%$ outside at-risk equity capital was needed to avoid consolidation) and in Paragraph 9 of FIN 46(R) established a $10 \%$ rule:

An equity investment at risk of less than 10 percent of the entity's total assets shall not be considered sufficient to permit the entity to finance its activities without subordinated financial support in addition to the equity investment unless the equity investment can be demonstrated to be sufficient.
} 
With the second criterion, we must consider if the holders of the equity investment at risk lack any one of the following three characteristics:

- The power, through voting rights or similar rights, to direct the activities of a legal entity that most significantly impact the entity's economic performance

- $\quad$ The obligation to absorb the expected losses of the legal entity

- $\quad$ The right to receive the expected residual returns of the legal entity? [FASB ASC 810-10-65-2]

Since, in this case, Ramona Technology (a wholly owned subsidiary of ABC Tech) is the general partner of Vimco and Vimco's board is not active, it would appear that ABC Tech can "direct the activities" of Vimco, while the limited partners (despite owning $80 \%$ of Vimco) lack the ability to direct the activities of Vimco with its inactive board. Additionally, since ABC Tech guarantees 60\% of Vimco's debt and Vimco has negative operating cash flows, it would seem that there is strong evidence that $\mathrm{ABC}$ Tech has the "obligation to absorb the expected losses of the legal entity", suggesting again that Vimco is a VIE. On the other hand, there would appear to be mixed evidence that $\mathrm{ABC}$ Tech has "the right to receive the expected residual returns" of Vimco (since these returns must be shared with the limited partners), but this sub-criterion does not need to be met since the previously described criteria have been met and Vimco is clearly a VIE.

For Step \#2, we consider if ABC Tech is Vimco's primary beneficiary. Both of the following criteria must be met for $\mathrm{ABC}$ Tech to be considered as Vimco's primary beneficiary:

- The reporting entity has "the power to direct the activities of a VIE that most significantly impact the VIE's economic performance."

- $\quad$ The reporting entity has "the obligation to absorb losses of the VIE that could potentially be significant to the VIE or the right to receive benefits from the VIE that could potentially be significant to the VIE."

In this case (as previously mentioned), Ramona Technology is wholly owned by ABC Tech and acts as the general partner for Vimco and thus has the "power to direct the activities" that "significantly impact [Vimco's] economic performance." The fact that Ramona Technology only owns $20 \%$ of Vimco is not controlling here because: 1) Ramona Technology has control over Vimco since Ramona Technology is Vimco's general partner and 2) Vimco does not have an active board which suggests that the limited partners that own $80 \%$ of Vimco have very little say in Vimco's operations.

Additionally, $\mathrm{ABC}$ Tech has the "obligation to absorb the losses" of Vimco since ABC Tech guaranteed about $60 \%$ of Vimco's debt and it seems likely that ABC Tech may be called upon to pay on these guarantees since Vimco has incurred negative operating cash flows and net losses in recent years.

Since the evidence is strong that both criteria are met for Step \#2, ABC Tech is deemed to be Vimco's primary beneficiary and consolidation is required per GAAP. From the evidence in the case, it is clear that ABC Tech has a controlling financial interest in Vimco.

One additional piece of evidence that suggests that $\mathrm{ABC}$ Tech is Vimco's primary beneficiary with a controlling financial interest in Vimco is provided by the $\$ 100$ million sale of inventory by ABC Tech to Vimco. Since there was a rather large (70\%) profit margin on this sale and Vimco has not been able to resell this inventory, this suggests that $\mathrm{ABC}$ Tech has the "power to direct the activities" of Vimco. The strong possibility exists that Vimco bought the inventory from $\mathrm{ABC}$ Tech to meet the profit needs of $\mathrm{ABC}$ Tech. Given the weak financials of Vimco, it does not seem reasonable for Vimco to buy this inventory from $A B C$ Tech at such a large markup. One can certainly question if an arm's length transaction was entered into by these two entities.

Consolidating ABC Tech and Vimco eliminates the concern about the apparent lack of an arm's length transaction since profits on intercompany sales would be eliminated until a subsequent sale was made to an unrelated $3^{\text {rd }}$ party. In ABC Tech's 2010 consolidated financial statements, the $\$ 70$ million profit on the $\$ 100$ million 2010 downstream sale from ABC Tech to Vimco would need to be eliminated in consolidation since Vimco 
still has this inventory as of December 31, 2010. Backing out this $\$ 70$ million profit would dramatically reduce ABC Tech's 2010 net income from the initial unaudited figure of \$251 million mentioned in the case materials.

2. Is there sufficient evidence, in your opinion, for your audit firm to insist upon consolidation with South Tech? Outline the evidence that supports or does not support consolidation with South Tech.

Overall, we believe the facts in the case (as discussed below) strongly suggest that $\mathrm{ABC}$ Tech is not required to consolidate its financial statements with South Tech.

As shown above with Vimco, we examine South Tech through a two-step process: 1) determine if South Tech is a VIE and 2) if South Tech is found to be a VIE, determine if ABC Tech is the primary beneficiary of South Tech.

As we saw with Vimco, for Step \#1 there are two criteria to consider and only one has to be met to establish an entity in question as a VIE. With the first criterion, we need to consider if equity investors have sufficient equity at risk for the legal entity to finance its activities without additional subordinated financial support. Evidence that subordinated financial support is needed includes equity of less than $10 \%$ of assets and significant guarantees of the entity's debt by the sponsoring company.

Per the case materials, South Tech is thinly capitalized with only $\$ 72$ million in equity (which is only $12 \%$ of South Tech's $\$ 600$ million in assets). Thus, South Tech's equity-to-assets ratio is somewhat above the minimum $10 \%$ FASB guideline. Additionally, ABC Tech has guaranteed $30 \%{ }^{5}$ of South Tech's debt which is a significant amount but not the majority of South Tech's debt. It should also be noted that ABC Tech set up South Tech a few years ago and the CEO of ABC Tech sits on the board of directors of South Tech and owns 10\% of South Tech's shares. Although the facts above suggest a gray area with respect to the question of the need for subordinated financial support (since South Tech's equity is more than 10\% of its assets and $\mathrm{ABC}$ Tech's loan guarantees are less than 50\% of South Tech's total debt), the fact that ABC Tech is the sponsoring company of South Tech, still has its CEO on the board of directors of South Tech, and is guaranteeing significant debt for South Tech is suggestive that, to be cautious, South Tech be considered a VIE.

Since we believe there is enough evidence to suggest that the first criterion is met, students would not be required to consider the second criterion since only one criterion needs to be met for an entity to be considered as a VIE. Though not required, below we discuss the second criterion where we consider if the holders of the equity investment at risk lack any one of the following three characteristics:

- The power, through voting rights or similar rights, to direct the activities of a legal entity that most significantly impact the entity's economic performance

- The obligation to absorb the expected losses of the legal entity

- $\quad$ The right to receive the expected residual returns of the legal entity? [FASB ASC 810-10-65-2]

Here there is no evidence to suggest that this criterion is met. Outside investors own $90 \%$ of the board seats and therefore appear to have the power to "direct the activities" of South Tech. Additionally, these outside investors appear to have the obligation to absorb losses and the right to receive expected residual returns from South Tech. Thus, there is no support that the second criterion is met.

To recap Step \#1, only one criterion needs to be met for South Tech to be considered a VIE. There is mild support that the first criterion is met and there is no support that the second criterion is met. Since we believe that the first criterion is met, we believe that South Tech should be considered as a VIE, forcing us to look at Step \#2 to determine if $\mathrm{ABC}$ Tech is South Tech's primary beneficiary.

\footnotetext{
${ }^{5}$ ABC Tech has guaranteed considerable debt on behalf of South Tech $(\$ 62$ million in letters of credit $+\$ 96$ million in trade obligations $=\$ 158$ million total debt guaranteed--which is 30\% of South Tech's total debt of $\$ 528$ million) which provides evidence that $\mathrm{ABC}$ Tech has "the obligation to absorb losses of the entity that could potentially be significant to the variable interest entity."
} 
For Step \#2, we consider two criteria that both must be met for ABC Tech to be considered as South Tech's primary beneficiary:

- $\quad$ The reporting entity has "the power to direct the activities of a VIE that most significantly impact the VIE's economic performance."

- $\quad$ The reporting entity has "the obligation to absorb losses of the VIE that could potentially be significant to the VIE or the right to receive benefits from the VIE that could potentially be significant to the VIE."

We believe that the first criterion is not met since there is insufficient evidence in the case that $\mathrm{ABC}$ Tech has the power to "direct the activities" of the VIE. Outside investors own $90 \%$ of the shares of South Tech and they would appear to be in a position to control the operations of South Tech since the board is described in the case as being fairly active. The CEO of ABC Tech, Mr. Lloyd, is also of the board of South Tech, but Mr. Lloyd only owns $10 \%$ of South Tech's shares and only controls $10 \%$ of the board seats which suggests that he does not have operational control of South Tech. ${ }^{6}$ Additionally, there have been no inter-company transactions between ABC Tech and South Tech which provides more evidence that ABC Tech is not able to direct the activities of South Tech.

Since this first criterion is not met (and both criteria must be met for ABC Tech to be considered as South Tech's primary beneficiary), ABC Tech is not deemed to be the primary beneficiary of South Tech. ABC Tech does not have a controlling financial interest in South Tech and consolidation is not required.

With the first criterion not being met, the second criterion does not need to be considered since ABC Tech has already been shown to not be the primary beneficiary of South Tech. For illustrative purposes, below we discuss our analysis of the second criterion within Step \#2.

Overall, we believe (for the second criterion) that there is support for the assertion that $\mathrm{ABC}$ Tech has the "obligation to absorb the losses of the VIE that could be significant to the VIE." ABC Tech guarantees $30 \%$ of South Tech's debt and given that South Tech has recently incurred negative operating cash flows and net losses, there is a reasonable likelihood that $\mathrm{ABC}$ Tech will have to make good on its significant guarantees of South Tech debt.

Overall, we believe that the first criterion is not met and the second criterion is met. Since both criteria are not met, we believe that $\mathrm{ABC}$ Tech is not the primary beneficiary of South Tech and consolidation is not required.

3. Does FASB ASC 450's (previously FASB 5) concern with contingent liabilities have any bearing on this case? If so, explain the implications of this standard on the accounting for the two VIE's in this case.

With Vimco, GAAP standards with respect to consolidation supersede any contingent liability considerations. Since Vimco meets the consolidation criteria noted above, all of Vimco's assets and liabilities (and not just the portion of Vimco's liabilities guaranteed by ABC Tech) would be consolidated with ABC Tech's balance sheet in consolidation.

With South Tech, on the other hand, above we argue that consolidation between ABC Tech and South Tech is not required per GAAP standards. Since consolidation is not required, consideration must be made with respect to the debt that ABC Tech guarantees for South Tech. FASB ASC 450 (formerly FASB 5) shows current GAAP with respect to loss contingencies. Per FASB ASC 450, if the likelihood of loss (from, for example, a loan guarantee) is deemed to be probable, the company making the loan guarantee must book a liability for the contingent obligation, but only if the loss can be reasonably estimated (FASB ASC 450-20-25). If the likelihood of loss is reasonably possible, then the company making the loan guarantee only needs to make a footnote disclosure with respect to the contingent obligation. If the likelihood of loss is remote, then no footnote disclosure is required.

\footnotetext{
${ }^{6}$ Since Mr. Lloyd, the CEO of ABC Tech, serves on the board of directors of South Tech and owns $10 \%$ of the voting stock of South Tech, Paragraph 14 of FIN 46(R) would suggest that Mr. Lloyd is a de facto agent of ABC Tech since he is "a member of the governing board of the enterprise." While Mr. Lloyd's ownership share is deemed to be too small to require consolidation, it would appear appropriate to footnote disclose the related party nature of the relationship per FASB 57.
} 
Applying FASB ASC 450, with respect to the loan guarantees that ABC Tech made on behalf of South Tech, requires that judgment be made with respect to the likelihood that South Tech will default on its loans that are guaranteed by $\mathrm{ABC}$ Tech. The case materials make no mention of South Tech ever defaulting on any loans and South Tech has positive owners' equity equal to $12 \%$ of its assets. On the other hand, South Tech has incurred negative operating cash flows and net losses over the most recent two year period. Most students, in their case writeups, have looked at this information and made the judgment that the likelihood that South Tech will default and $\mathrm{ABC}$ Tech will have to make good on its loan guarantees is reasonably possible and these students recommend that $\mathrm{ABC}$ Tech make a footnote disclosure with respect to this $\$ 158$ million contingent obligation.

4. Compute the impact on ABC Tech's debt-to-assets ratio if Vimco and/or South Tech were consolidated with its sponsoring company. Assess the risk of ABC Tech's ability to continue as a going concern if Vimco and/or South Tech defaulted on their loans.

As a stand-alone company, $\mathrm{ABC}$ Tech is already highly leveraged with a debt-to-assets ratio of $85 \%$ (liabilities of $\$ 5,100$ million divided by assets of $\$ 6,000$ million). If Vimco consolidated with $\mathrm{ABC}$ Tech, it would add $\$ 1,000$ million in liabilities and $\$ 950$ million in assets to ABC Tech's consolidated balance sheet. After consolidation with Vimco, ABC Tech would have $\$ 6,100$ million in liabilities and $\$ 6,950$ million in assets resulting in a debt-to-assets ratio of $87.8 \%$.

If South Tech was not consolidated and if the contingent obligation, with respect to South Tech's debt that was guaranteed with by ABC Tech, was only footnote disclosed, South Tech would have no impact on ABC Tech's consolidated balance sheet. On the other hand, some students may argue that the case presents evidence to support the judgment call that the likelihood that $\mathrm{ABC}$ Tech will need to make good on the $\$ 158$ million debt guaranteed to South Tech is probable (and subject to reasonable estimation). These students would apply FASB ASC 450 and suggest that $\mathrm{ABC}$ Tech needs to book additional contingent liabilities on its balance sheet. If the entire $\$ 158$ million contingent obligation is added to ABC Tech's consolidated liabilities, total consolidated liabilities will be $\$ 6,258$ million and consolidated assets will still be $\$ 6,950$ million, resulting is a debt-to-assets ratio of $90.0 \%$.

Overall, it can be seen why the CEO of ABC Tech is strongly opposed to consolidation with respect to his company's VIE's (as consolidation will increase the company's already high debt-to-assets ratio). Additionally, applying FASB ASC 450 to the debt guaranteed by ABC Tech on behalf of South Tech (if the risk of loss with respect to guaranteed debt is argued to be probable) presents an even bleaker picture of ABC Tech's debt-to-assets ratio.

While Vimco and South Tech have major going concern issues with their negative earnings, negative operating cash flows, and thin capitalization, $\mathrm{ABC}$ Tech itself seems to be solvent, at this time, with positive earnings. Consolidation would reduce ABC Tech's profits since Vimco's 2010 net loss of \$-85 million would reduce ABC Tech's consolidated income and the $\$ 70$ million profit on intercompany sales from ABC Tech to Vimco would need to be eliminated in consolidation until the inventory was sold to an outside third party. After these adjustments in consolidation, it would seem that $\mathrm{ABC}$ Tech would still be modestly profitable since the company's unaudited preliminary net income was $\$ 251$ million in 2010. However, with a debt-to-assets ratio higher than $85 \%$, the consolidated company could easily develop going concern issues if earnings and/or operating cash flows decrease slightly in the future. Additionally, the higher debt-to-assets ratio and the decreased earnings that come from consolidation for $\mathrm{ABC}$ Tech is likely to lead to increased interest rates when $\mathrm{ABC}$ Tech needs to obtain new debt financing. Higher interest charges would increase going concern risk.

5. What is your overall recommendation to Robert and Sharon? Do you think that your firm should bid on this potential client based on the information that has been gathered thus far?

Most students recommend that their audit firm insist upon consolidation for Vimco (but not for South Tech). Many students argue that their audit firm should only submit a bid to try to win this new client if ABC Tech agrees to consolidate with Vimco. On the other hand, many other students typically argue instead that the risk of submitting a bid on this client is too great and these students recommend that their firm decline to bid on the $\mathrm{ABC}$ Tech audit. The students recommending that their firm not bid will usually mention some combination of the 
following risk factors: 1) the very high debt-to-assets ratio of $\mathrm{ABC}$ Tech which only gets worse with consolidation, 2) the lack of concern by ABC Tech's top management about the audit fee, combined with an obsession with trying to avoid consolidation, and 3) related party transactions (this last risk would be mitigated with consolidation). Students recommending "no bid" tend to be worried that ABC Tech's top management may become so aggressive in its financial reporting practices that its behavior becomes unethical.

\section{Assessment Data}

We asked our students $(n=214)$ to fill out a short one-page survey after they completed the writing assignment. Here is the breakdown on a question we asked about whether students perceived the case to be a useful exercise:
- $\quad 47 \%$ agreed strongly
- $\quad 48 \%$ agreed somewhat
- $5 \%$ disagreed somewhat
- $\quad 0 \%$ disagreed strongly

Overall, our students believed that the case was a useful exercise.

We also asked if our students $(n=214)$ thought that the case was realistic. Here is the breakdown on the question about whether students perceived that the case was realistic:

$$
\begin{aligned}
& -\quad 46 \% \text { agreed strongly } \\
& -\quad 49 \% \text { agreed somewhat } \\
& \text { - } \quad 5 \% \text { disagreed somewhat } \\
& \text { - } \quad 0 \% \text { disagreed strongly }
\end{aligned}
$$

Overall, our students believed that the case was realistic.

Students were asked the following open-ended question: "What were the key benefits from doing the case?" Many students responded that they appreciated the opportunity to research FASB standards for this case and the opportunity to write a professional memo. Here are some illustrative responses:

- I learned that there is a significant difference between writing [term] papers and writing business letters \& memos.

- $\quad$ Learning how to critically write

- $\quad$ Rewriting and revising the case using your help was probably the most beneficial learning aspect. Working through the case to understand FASB rules allowed me to learn how to read the rules and understand what they meant.

Students were also asked the following open-ended questions: "What are the key weaknesses in the case? How do you think that the case could be improved in the future?" The most common response was that students said they would have liked more structure (maybe a mini-lecture on variable interest entities) before starting to work on the case. In response to these comments, the authors now give a mini lecture to give the students a bit of structure, while being careful to let students discover for themselves the key elements within GAAP standards that need to be applied to this case. Here are some illustrative student responses:

- I had a hard time understanding some of the language of the standards. Maybe add a little overview on the standards.

- $\quad$ FIN46R was very confusing to interpret. Maybe next time give us a little more direction.

- I wish there was more of a right answer. 
With respect to this last comment, many students, when doing this case, have been surprised by how much judgment is required on their part to come up with the "right" answer. Students oftentimes are looking for some kind of clear cut litmus test that will give them the answer to the case. Instead, our students find out, as they work through this case, that there really is no substitute for professional judgment.

\section{CONCLUDING COMMENTS}

We found this case to be very useful in our Advanced Accounting classes since consolidation is an important topic within this class and most students can see the relevance of a case dealing with the consolidation (or non-consolidation) of variable interest entities. We change all the financial figures, the company name and personnel names each semester to help preserve the integrity of the learning exercise.

Some students taking Advanced Accounting at our university will already have taken the Auditing class or will be taking Auditing concurrently with Advanced Accounting. Other students will not have taken the Auditing class yet and may have some anxiety with respect to the case, which is set in an auditing environment. To mitigate this anxiety, we have the case set up where no audit work is being done and no audit opinion needs to be expressed. Instead, this case involves preliminary work to determine if a bid should be made for the upcoming audit and if the audit firm should insist upon consolidation. We have found it helpful to spend a few minutes in class to explain the auditing environment as it relates to this case and we have also found it useful to explain to students that this is an Advanced Accounting assignment and not an Auditing assignment (and that students will not be expected to develop Auditing concepts for this professional memo).

\section{AUTHOR INFORMATION}

Timothy Kelley, Professor of Accounting, formerly worked with the CPA firm Arthur Andersen \& Co. Dr. Kelley has been teaching at the University of San Diego since 1983 and his primary teaching interests are financial and managerial accounting. Most of his research has focused on the impact of time pressures on the work environment of auditors working in public accounting. He has published articles in the following journals: Auditing: A Journal of Practice and Theory, Advances in Accounting, Accounting Horizons, The Journal of Applied Business Research, The CPA Journal, National Public Accountant and The Journal of College Teaching \& Learning. E-mail: tkelley@sandiego.edu. Corresponding author.

Loren Margheim, Professor of Accounting, joined the University of San Diego in 1984. He received his CPA certificate in 1979. Dr. Margheim's specialties are in corporate financial reporting and auditing. His research has generally focused on factors affecting the behavior of auditors while performing audits. Specifically, he has performed research that has identified factors that cause auditors to engage in dysfunctional behaviors during their audits. He has also extensively examined how the work performed by a corporation's internal auditors affects the work of their external CPA's. His research papers have appeared in such journals as Journal of Accounting Research, Advances in Accounting, Auditing: A Journal of Theory and Practice, and Accounting Horizons. E-mail: margheim@sandiego.edu. 
NOTES 